\title{
WACIKA PARISUDA : ETIKA UJARAN DALAM HINDU
}

\author{
Wentin \\ Jurusan Dharma Duta STAHN-TP Palangka Raya \\ wentin@stahntp.ac.id
}

\begin{abstract}
This paper is an explanation of the ethical teaching of speech according to Hinduism. In Hinduism, the quality of one's self is measured at least on three aspects of action, known as Tri Kaya Parisuda (Three Good or noble Behavior), 1) Manacika (good thinking), 2) Wacika (good speech), and 3) Kayika (good action). All three things must be actualized in a balanced way. If there is lameness in one of the other aspects, it will have a bad effect. Man is recognized by the way he thinks, speaks and acts. This paper traces the teachings of wacika parisuda (good speech) from various sources in Hindu literature. In the study of Hindu literature (Nitisastra, Slokantara, Sarasamuccaya, Bhagavadgita) shows that a person's utterance indicates his maturity, knowledge, and spirituality.
\end{abstract}

Keywords: Ethic, Tri Kaya Parisuda, Wacika Parisuda

\section{PENDAHULUAN}

Dalam dunia pedagogis, kedewasaan merupakan akumulasi atas matangnya banyak dimensi, diantaranya adalah; dimensi religius, logika, etika, estetika dan lainnya. Salah satu indikator populer dalam mengukur kedewasaan, sangat ditentukan oleh seberapa baik seseorang tersebut mampu mengelola dimensi etik-nya. Etika (KBBI, 2003:383) dalam pengertian umum dipahami sebagai ilmu tentang apa yang baik dan apa yang buruk dan tentang hak serta kewajiban moral (akhlak). Oleh sebab itu etika sering persamakan dengan moralitas atau ahklak. Dari penjelasan ini kiranya dapat dipahami bahwa membahas mengenai etika, sudah tentu terkait dengan tindakan atau perilaku.

Berbicara kata merupakan sub bagian dari dimensi etika yang memiliki ruang lingkup sangat luas tentunya. Berbicara merupakan media dimana nilai-nilai etika teraktualisasi, sekaligus tervisualisasikan. Karena setiap orang (dalam parameter umum tentunya) dapat memilah atau membedakan mana pembicaraan yang baik dan tidak baik. Manusia memiliki intensitas berbicara sangat tinggi, namun belum tentu setiap tutur katanya mendapat pengelolaan atau perhatian yang sebanding dengan intensitasnya. Singkatnya, setiap orang belum tentu memperhatikan setiap ucapannya agar menjadi satu 
pembicaraan yang baik dan bermanfaat untuk dirinya maupun lawan bicaranya. Indikasinya adalah masih banyak dijumpai pada setiap komunikasi verbal dalam masyarakat kita yang berujung pada satu situasi yang kurang harmonis. Contoh, dalam komunikasinya menimbulkan kemarahan, kekecewaan, kebencian, dendam, atau bahkan berujung pada pertengkaran, entah itu diakibatkan dari perkataan yang bernada kasar, angkuh, sombong, menyindir, mencela, memfitnah, dan sebagainya.

Dalam penelaahan lebih jauh, berbicara tidak sekadar pergulatan nilai etika namun yang jauh lebih urgent adalah setiap berbicara (yang wajar atau dengan motif tidak dibuat-buat karena alasan tertentu) merepresentasikan kualitas pribadi si empunya. Simpulan (hipotesa) ini mungkin terasa sangat prematur, subjektif, relatif dan bahkan dapat diperdebatkan, namun dalam situasi normal kita dapat melihat fenomena ini pada keseharian. Misalnya, kita dapat membedakan cara atau gaya berbicara anak-anak, remaja, pemuda, orang tua, orang yang temperamental, orang yang santun dan sebagainya. Paling tidak ini dapat dijadikan acuan dari penyimpulan di atas.

Tak disangkal lagi bahwa berbicara memiliki kontribusi besar atas matanganya dimensi etika, yang kelak memiliki peran signifikan dalam proses pendewasaan seseorang. Orang yang mampu mewujudkan totalitas akal budhi (pengalaman dan pengetahuan) dalam setiap bicaranya adalah orang yang bijaksana dalam berbicara, sehingga dalam setiap pembicaraannya tidak hanya komunikatif, efektif tetapi juga membuat lawan bicara menjadi nyaman, t eduh, menyenangkan dan menumbuhkan suasana keakraban, keharmonisan serta kesan yang baik, dan bukan sebaliknya.

Dalam konteks ini, Hindu memberikan porsi pengetahuan yang melimpah. Halhal yang berkaitan dalam aktivitas bicara manusia (wicara, berbicara) banyak disinggung dalam kesusastraan Hindu. Tulisan ini bermaksud untuk mengungkap bagaimana mutiara etika Hindu khususnya yang berkaitan dengan wicara (wacika), mencoba untuk diungkapkan dari berbagai kitab suci. Harapannya, akan dapat dijadikan referensi tentang etika berbicara (wacika) secara teoritik sekaligus memahami bagaimana Hindu begitu serius dan total dalam mewacanakan ajaran-ajaran moralnya.

\section{Pembahasan}

Dalam Pandangan Hindu, kualitas diri seseorang diukur paling tidak atas tiga aspek tindakan, yang dikenal dengan Tri Kaya Parisuda (Tiga Tingkah laku yang baik atau mulia), yaitu : 1) Manacika (berpikir yang baik), 
2) Wacika (berkata yang baik), dan 3) Kayika ( berbuat yang baik) (Suhardana, 2006:28). Ketiga hal di atas harus selaras dan teraktualisasi secara utuh. Salah satu terjadi kepincangan dan ketidaksesuaian dengan dua aspek lainnya, akan memberikan nilai kurang baik bagi manusia itu sendiri. Memang tidak mudah, tetapi demikianlah salah satu prasyarat Hindu bila ingin menjadi pribadi yang baik.

Sebagaimana yang dijelaskan di atas, salah satu aspek dari ketiga hal di atas (Tri Kaya Parisuda), adalah wacika parisuda, yaitu bagaimana manusia mengupayakan dirinya untuk senantiasa memastikan bahwa apa yang diucapkan merupakan kebajikan, mengandung nilai-nilai luhur dan tidak menyakiti yang lain. Hindu memiliki perhatian serius tentang aktivitas "berucap atau berbicara" manusia. Sebab, ucapan memberikan dampak luar biasa bagi si empunya ucapan. Demikian dinyatakan dalam Nitisastra V.3 :

Wasita nimittanta manmu laksmi Wasita nimittanta pati kapangguh Wasita nimittanta manmu duhka Wasita nimittanta manmu mitra

Terjemahan :

Oleh perkataan engkau akan mendapatkan bahagia

Oleh perkataan engkau akan memperoleh kematian

Oleh perkataan engkau akan mendapatkan kedukaan

Oleh perkataan engkau akan mendapatkan sahabat
Ada ungkapan yang sering kita dengar dalam keseharian kita "mulutmu harimau mu". Dalam pelbagai kenyataan hidup kita paling tidak pernah mengalami bagaimana kata-kata atau ucapan tersebut mmberikan efek batin bagi kita, entah itu bahagia ataupun duka. Kita acapkali merasa tidak nyaman karena perkataan orang lain terhadap kita, demikian juga kita tentu pernah merasakan kesejukan dan keteduhan luar biasa karena perkataan baik kepada kita, kita merasa sangat berbahagia karena orang lain bersikap baik dalam kata-katanya ketika kita sedang berbicara dengannya. Dengan kata-kata kita menemukan sahabat yang baru, tapi tak tak jarang kita juga kehilangan teman karena perkataan kita. Pernyataan Nitisastra di atas sungguh benar adanya.

Salah satu hal penting yang dapat kita petik dari setiap perkataan manu sia adalah bahwa, ternyata perkataan seseorang sangat terkait erat dengan identitas dan kualitas pribadi seseorang. Hal ini mungkin sangat subyektif, namun tentunya setiap kita dapat mengamatinya dalam keseharian bagaimana korelasi antara identitas serta kualitas manusia dan ucapannya. Dalam Pandangan Hindu, kedua hal tersebut berkorelasi erat, demikian dinyatakan dalam Sarasamuccaya 77, yakni :

Apan ikang kinatahwan ikang wwang, kolahanya, 
kangenangenanya, kocapanya, ya juga bwat umalap ikang wwang, jenek katahwan irika wih, matangyan ikang hayu atika ngabhyas an, ring kaya, wak, manah.

Terjemahan :

Sebab yang membuat orang dikenal, adalah perbuatannya, pikirannya, ucapan-ucapannya; hal itulah yang sangat menarik perhatian orang, untuk mengetahui kepribadian seseorang; oleh karena itu hendaklah yang baik itu selalu dibiasakan dalam laksana, perkataan dan pikiran (Kajeng, 1999:64).

Sloka di atas menjelaskan bahwa identitas dan kualitas seseorang dapat dipahami dari ucapan-ucapannya. Dari sanalah kita akan dengan mudah untuk mengetahui bahwa seseorang itu rohaniawan ataupun pedagang, orang itu berpengetahuan luas atau sebaliknya, orang itu berbudi baik atau kurang baik. Sekali lagi ini sangat subyektif tetapi setiap kita dapat melihat, mengamati sekaligus membuktikannya dalam keseharian kita.

Pesan tentang kearifan tentang "ucapan" ini juga dapat dijumpai dalam Kitab Suci Sarasamuccaya 124, sebagai berikut:

Nakrocamicchenna mrsa vadecca napaisunyam

Janavadam na kuryat, satyavrato mitabhaso

Pramattasya vagdvaramupaiti guptim
Terjemahan :

Oleh karena itu, orang yang arif bijaksana, orang yang berjanji atas dirinya berpegang kepada kebenaran, tidak mencaci orang, tidak memfitnah, tidak mencela, lagi pula tidak berkata dusta melainkan giat berusaha menahan u c a pan-uc a pann y d a n memelihara agar orang lain jangan sampai terluka karenanya (Kajeng, 1999:102-103).

Pesan ini sangat relevan dan layak untuk dijadikan referensi dan refleksi dalam upaya memelihara proses komunikasi dan interaksi sosial yang baik kepada setiap orang, sekaligus sebagai upaya tiada henti dalam cita-cita serta tekad menjadi pribadi yang bijak dalam bicara.

Dalam Bharatayudha, di medan Kuruksetra Sri Kresna (Bhagawad Gita 17.15) menjelaskan mengenai pertapaan (pengendalian diri) dalam hal ucapan Demikian Krsna menjelaskan :

Anudvega-karam vakyam satyam priya-hitam ca yat svadhyayabhyasanam caiva van-mayam tapa ucyate

Terjemahan :

Kata-kata yang tidak melukai hati, dapat dipercaya, lemah lembut dan berguna, demikian pula membiasakan diri dalam mempelajari kitab-kitab suci, ini dinamakan bertapa dengan ucapan (Pudja, 1999:394).

Hal serupa juga dinyatakan dalam sloka 6.5-6.7 Bhagavad Gita, Dalam 
Slokantara 47, dijelaskan bahwa, salah satu cara untuk menguji baik atau buruknya sifat seseorang adalah dengan memperhatikan kata-kata dan cara menyampaikannya. Demikian yang dinyatakan dalam Slokantara :

Kalingannya, tingkah ing sang mahyun amariksa hala-hayu ning janma wwang, nem prakaranya, ndya ta, akarangaranya papindan ing rupanya tinghalana, tembeyanya, inggita ngarannya ringaringanen sasmitanya, tinghalaken polahnya, gati ngaranya lakunya tinghalana, kaping tiganya, cesta ngaranya ketegtig ing awaknya tinghalana, kaping pat ika, bhasita ngaranya pangucap-ucapnya ingetakna, kaping limanya, hana ta muah panengeran ing wekasan, ring mukha mwang mata, yan wikara paninghalanya, wikara ngaranya hana renggat ing mata lawan mukha katon, apan ulat ing durjana mengas chala-mukhanya, apan mengas atinya, apan hatinya mesi kadustan, mangkana tingkah ing wwang yan masadhya hala, kunang sang sadhu tumungkul ararem santa somya mamanisi tinghal ira, apan dalem ing hati nira tan pasadhya hala, kewala nirmala sada, mangkana kramanya ling sang hyang sastra.

Terjemahan:

Jalan yang harus ditempuh oleh mereka yang ingin menguji baik atau buruk sifat seseorang itu ada enam macam; akara, yaitu dengan memperhatikan bentuk luar tubuhnya, ini ujian pertama. Inggita, artinya bahwa gerak geriknya harus diperhatikan, tingkahnya harus diselidiki. Gati, artinya caranya berjalan harus diperhatikan, inilah ujian ketiga. Cesta, adat kebiasaannya harus diperhatikan, ini ujian keempat. Bhasita, yaitu kita harus perhatikan kata-kata dan caranya mengatakan, ini yang kelima. Sekarang ujian terakhir yang harus diperhatikan "wikara" yang ada pada muka dan matanya. Wikara, artinya perubahan air muka dan gerak mata. Memang banyak perbedaan dalam pandangan orang yang berniat jahat dengan yang baik gerak-geriknya memuakkan perut, dan mukanya penuh bayangan kejahatan karena hatinya serong dan jahat. Demikianlah bayangan air muka orang yang berhati jahat; sebaliknya, orang yang berbudi tinggi itu kelihatan merendah, ramah, tenang, manis dan menyenangkan hati barang siapa melihatnya. Perasaan tidak pernah dibayangi oleh kejahatan. Hatinya tidak pernah dinodai oleh keinginan untuk berdosa. Demikianlah tingkah laku mereka menurut kitab suci (Sudharta, 2004:161-162).

Slokantara sloka 6 juga menyinggung mengenai berbicara yang baik. Dikatakan bahwa seorang yang telah maju dalam kerohanian, bijaksana, sebagai representasi manusia dengan moralitas tinggi (pendeta, resi, sanyasa, brahmana, dst.) menyaratkan telah usainya mereka dengan moral berbicara ini. Artinya, moralitas seseorang sangat ditentukan juga, atau sangat tampak dalam kata-katanya. Pendeknya, orang 
yang belum mampu berbicara yang baik (luhur, sopan, mulia, dst.) belum layak dikatakan sebagai orang yang arif atau yang memiliki moralitas yang baik. Demikian dijelaskan :

Kalinganya, ulaha sang tapa, bhujangga saiwasiddhanta, dharma gawayakna, sila nira rahayu pagehakna, haywa manabuddhi, jitaka ikang mana, haywa matukar lawan para, yeka rosa ngaranya, haywa katunan widya wruha ring sarwasastra kabeh, tan butuhan ing patakwan ri sarwagama pramana, slokadiwakya, mwang hala-hayu ning rat, haywa mamanasi sama janma, yan amuwus madhurawacana, tusta dening swadara, swadara ngaranya rabi prihawak, yeka hetu nira winenangakena rabi papat, paradarawarji ngaranya haywa mangangen-angena stri ning para, yeka donya yan mangkana, tan hana bhaya nira ring loka, kunang sira yan linaran dening para, tan sayogya dosa nira, kinkinen, tan pinakaduhkha, ning manah: uttama, angucap ing lara nira ri dalem hati: madhyama, yan angucap lara nira met ring sabda: kanistha, yapwan amadani halanya: kanistha ning kanistha yan mangkana, ling sang hyang aji.

Terjemahan :

Kewajiban seorang pendeta, pertapa, dan pengikut ajaran Siwa Siddhanta ialah melaksanakan dharma (kewajiban suci). Ia harus teguh hati dalam menjalankan kebenaran. Ia tidak boleh sombong, perasaan tinggi diri itu harus dihilangkan. Ia tidak boleh berkelahidengan siapapun. Berkelahi itu dinamai dosa. Ia harus tidak picik pengetahuan, yaitu ia harus tahu dengan mendalami segala ilmu. Pengetahuannya harus mendalami tentang isi kitab suci, tentang sloka-sloka ajaran susila dan segalanya yang dianggap baik dan b u r u k, un t u k d a p a t membedakannya. Jangan gendaknya menyakiti hati orang lain. Kalau berbicara pakailah kata-kata manis menyedapkan. Ia harus puas dan tetap setia pada istrinya sendiri, dan untuk ini sudah diperbolehkan beristri sampai empat orang jika perlu. Paradarawarji artinya ia tidak boleh merindukan istri orang lain. Jika sudah demikian kelakuan dan tujuan hidupnya ia tidak akan mempunyai perasaan takut atau sangsi terhadap apa dan siapa pun di dunia ini. Dan jika seandainya orang lain masih juga menyakiti atau mencela, menjahati dia, maka ia tidak boleh mengutuk orang itu. Tegasnya, jika seseorang itu tidak perduli pada kejahatan yang ditimpakan kepadanya oleh orang lain, dia itu orang utama. Tetapi jika orang itu merasa di dalam hati bahwa dirinya disakiti ia termasuk golongan madhya (menengah). D a n jika orang it u memperlihatkan perasaan sakit hatinya dengan kata-kata, ia itu termasuk orang tingkat rendah (kanistha). Dan akhirnya jika orang itu membalas sakit hatinya dengan perbuatan yang setimpal dengan apa yang telah dilakukan terhadap dirinya, ia itu orang yang paling rendah.

Demikianlah ajaran kitab suci. 
Masih dalam kitab Slokantara, yakni pada sloka 16 diberikan contoh yang sangat jelas, bagaimana, pe mbicaraan it u sangat mengindikasikan moralitas seseorang. Ini semakin menegaskan dari penjelasan sloka sebelumnya, yakni moralitas seseorang juga diukur dari caranya berbicara. Yang perlu dicamkan adalah bahwa wacana ini berada dalam situasi yang normal, bukan untuk kepentingan politis atau mengada-ada. Maksudnya, ini tidak berlaku pada situasi misalnya, orang sedang berkata-kata yang lembut, manis dan menyenangkan hati, untuk tujuan tertentu, misalnya agar dianggap bermoral, untuk menipu seseorang, agar mendapatkan simpati kemudian dipilih dalam jabatan tertentu, atau untuk kampanye dalam pemilukada, dan sebagainya. Seklai lagi ini dalam konteks situasi normal. Demikian dijelaskan :

Kalinganya, yan hana wwang masangsarga lawan wwang nica, niyata nika katularan buddhi durjana nica, mangkana yan asangsarga lawan ikang wwang sadhu, katularan budhi sadhu, drstopamanyatah, kadyangga nikang atat rwang siki, mangaran si Gawaksa, mwang si Girika, ikang sasiki, inalap ing tuha buru, iningu nika, ikang sasiki, inalap de sang pandita, iningu nira, kathancit hana ta sira ratu maburu-buru, kasasar ta sira prihawak, kuwawa marery umah ning tuha buru, kahanan ikang atat si Girika, mojar tekang atat ring sang prabhu, lingnya, ndah mah ta mah, siwak kapalanya, mangkana ta wuwus nikang atat, karengo de sang prabhu, alayu ta sira rumengo wuwusnya, ri wekasan ta sira, kawawa mareng patapan sang pandita, ri kahanan ikang atat si Gawaksa, mojar ta ya, lingnya, dhuh bhagya ta kita sang prabhu, dingaryan ta rahadyan sangulun, kasepera ring patapan, araryana ta laki, alungguha ring widig anar, anginanga wwah ampiji, mwang sere hanar, apuh mentah, yapwan anghel rahadyan sanghulun, madamwa sri maharaja, irikang walukan, mangka ling nikang atat ri sira, kascaryan ta manah nira sang prabhu, rumengwaken ujar ikang atat, ri wekasan ta sang $p$ rabhu, matakwan ri sang pandita, irikang atat iningu nira, mojar ta sang pandita, yan kawawa dening sangsarga nika, sangskepa nika sang sadhujana, haywa sira tan pamilihi sangsarga nira, ikang sayogyamu wuhana $g$ una ri sira, haywa sira masangsarga lawan ikang wwang durjana, apan amawa mareng kawah, ling sang hyang aji.

Terjemahan :

Jika ada orang yang bergaul dengan orang yang berbudi rendah, pasti dia akan dipengaruhi oleh kerendahan dan kejahatan budi kawannya itu. Demikian juga jika kita bergaul dengan orang baik, sudha pasti ia akan dipengaruhi budi baik mereka itu. Hal ini dapat disamakan dengan cerita dua ekor burung beo bernama Gawaksa dan Girika. Seekor dipelihara dan dilatih oleh seorang pemburu. Yang lainnya dipelihara dan dilatih oleh seorang 
pendeta agung. Suatu hari ada seorang raja yang sedang berburu dan tersesat sendirian saja, hingga akhirnya baginda sampai ke rumah pemburu itu, yang ditunggui oleh burung beo bernama Girika. Burung itu berkata kepada raja, "Nah ini dia, ini dia datang, bunuh saja, potong lehernya". Demikianlah kata-kata burung ini yang menyebabkan raja itu ketakutan dan lari dari tempat itu sehingga akhirnya baginda sampai di pertapaan Sang Pendeta yang dijaga oleh burung beo yang bernama Si Gawaksa. Burung itu berkata, "Kami bahagia Tuanku, karena Tuanku telah sudi mampir ke pertapaan ini. Beristirahatlah di sini, Tuanku. Silakan Tuanku duduk di tikar baru itu. Maafkan sajian kami berupa buah pinang yang agak keras, daun sirih muda, dan kapur mentah ini. Nampaknya Tuanku telah berpayah-payah benar hingga sampai kemari. Silakan segarkan badan Tuanku dengan istirahat di telaga permandian itu. Demikian ucapan burung itu, sehingga baginda terperanjat mendengarnya. Baginda lalu bertanya dengan sang pendeta tentang burung yang dipelihara di asrama itu. Dan sang pendeta berkata bahwa burung itu dipelihara dari kecil sampai besar dan dipengaruhi oleh keadaan sehari-hari sang pendeta. Tegasnya orang-orang baik janganlah lengah sehingga salah dalam mencari kawan pergaulan. Haruslah diusahakan mencari kawan yang dengan pergaulan itu, dapat mempertinggi pribadi sendiri. Jangan sekali-kali bergaul dengan orang jahat karena pergaulan demikian akan membawa ke neraka .
Demikianlah kitab suci.

Dalam Nitisastra 1.6. yang menjelaskan mengenai cara-cara bagaimana untuk mengetahui sifat, keturunan, dan budi seseorang. Demikian disampaikan :

Jroning wwe parimana nala gaganging tunjung dawut kawruhi. Yan ring jatikula pracara winaya mwang sila karmenggita. Yan ring pandita ring ksamamudita santopeksa rismardawa. Sang sastrajna wuwunirameta padanyangde sutusteng ngpraja

Terjemahan :

Untuk mengetahui dalamnya air sebuah telaga, cabutlah batang teratai untuk menduganya. Jika $h$ e $\mathrm{nd} \mathrm{a} \mathrm{k} \mathrm{m} \mathrm{e} \mathrm{n} \mathrm{g} \mathrm{e} \mathrm{k}$ a u i kebangsawanan seseorang, kita harus perhatikan tingkah laku dan sopan santunnya. Jika ingin mengetahui kesucian seseorang, harus dilihat kesabarannya; kerendahan hat in ya, $\mathrm{k}$ e te $\mathrm{n}$ a $\mathrm{ng}$ a n $\mathrm{n}$ a, $\mathrm{d}$ a $\mathrm{n}$ keikhlasannya. Sebagai ciri orang yang berilmu ialah kata-katanya sama dengan air kehidupan yang menjadikan hati rakyat tenang dan amat bahagia (Sudharta, 2004:162).

Slokantara Sloka 72, menjelaskan bahwa berkata yang baik, selalu berkata sopan dan tidak menyakiti hati orang lain (maitri), merupakan etika yang hendaknya dilakukan, bahkan sebagai keharusan bagi orang-orang yang ingin menapaki jalan dharma. Maitri adalah tujuan hidup utama bagi orang-orang 
yang berada pada jalan dharma. Artinya, kata-kata yang sopan dan tidak menyakiti hati orang lain merupakan praktik disiplin moral bagi manusia yang baik. Demikian dijelaskan :

Nihan dasa paramartha, kawruhakna de sang sewakadharma, sang tumaki-taki ambek awiratin, sang mahyun walwi manusajati, kang sangkan ing luput ing papa kawah, ya ta ulahakna ikang dasa paramartha. Ndya ta, tapa, brata, samadhi, santa, sanmata, karuna, karuni, upeksa, mudita, maitri. Kramanya, tapa nga ambek kawiratin. Brata nga anglongi sakawisaya ning mahurip. Samadhi nga sabda tunggal tan lenok. Sanmanta nga tunggal karep ira kewala ring karahaywan, dera gawayaken. Karuna nga awelas ri sasama ning mahurip. Karuni nga asih ring sarwa tumuwuh, muwah sakweh ing sarwa sato. Upeksa nga wruh ing hala-hayu, ata mamarahi ring wong mudha, maring apekik. Mudita nga ambek ayu legeng buddhi, tan purik yen pinituturan. Maitri nga aweh sabda rahayu ring sasama ning ahurip.

Nihan ambek dasa-mala nga, tan yogya ulahakna, lwirnya, tandri, kleda, leja, kuhaka, metraya, megata, raga-stri, kutila, bhaksabhuwana, (kimburu). Tandri ng wwang sungkana, leson balebeh sempeneh adoh ing rahayu, anghing hala juga kaharepnya. Kleda ng ambek angelem-elem, merangan maring harep, tan katekan pinaksanya. Leja nga ambek Tamah, agong trsna, agong lulut asih, maring hala. Kutila nga parachidra, pesta peda ring kawelas asih, pramada pracala nor ana wwang den keringi. Kuhaka nga ambek krodha, agong runtik, capalasabda, banggaporaka. Metraya nga bisagawe ujar mahala, sikaradumikara, wiwiki-wiweka, sapa kadi sira, botarsa rabi ning arabi, tan hana ulahnya rahayu, yan $m$ etu sabdanyarum amanis anghing hala ri dalem, tan papilih buddhi cawuh, kala ri hatinya purikan. Raga-stri nga bahud lanji wawadonan, rambang panon, bhaksa-bhuwana andenda sasama ning tumuwuh, akirya ring wwang sadhu, ardeng pangan inum, hangkara sabda prengkang. Kimburu nga anghing gawene akirya-kirya drewe ning wwang sadhu, tan papilih, nor kadangsanak-mitra, yata memet drewe ning sang wiku, mangkana krama ning dasa-mala, tan rahayu.

Nihan ambek nawa-sanga nga marapwan sira siddha rahayu, lwirnya, andrayuga, gunabhiksama, (Sadhuniragrha), widagdha prasanna, wirotasadharana, krtarajahita, tyaga prasanna, suralaksana, sura pratyayana, sanga kwehnya. Andrayuga nga prajna ning dharmatutur, watek angaji, widagdha wruh ring hala-hayu. Gunabhiksama nga sadhu sira ring artha ning gusti, lumanglang sira ring pakeweh, upeksa sira rorowang, anut sakrama ning wwang akweh, enak de nira Krta rahayu. Sadhuniragrha nga sadhu sira ring wawadon, tan cakep sira ring sama-sama wwang, Widagdha prasanna nga tan mamangan sira ingaturan sabda tan yogya, tan sungsut purik sira, prasannabuddhi nira enak. Wirotasadharana nga wani tan 
karahatan, (tan?) asor ing ujar, mrih ring niti. Krtarajahita nga wani asor, wruh ring Kutaramanawadi. Tyagaprasanna nga tan panengguh angel, yen ingutus dening gusti. Suralaksana nga tan anengguh wedi, enggal tan asuwe, surapratyayana nga bhakty agusti, sura-laksana ring paperangan, sumangga ring pakeweh, rumaksa ring gusti. Iti ambek nawangsa, kayatnakna kramanya, sowang-sowang, rahayu dahat, yan kalaksanan.

Terjemahan :

Inilah sepuluh paramartha (tujuan hidup utama), yang harus diketahui oleh orang menjalankan dharma. Orang yang ingin melepaskan pikirannya dari hidup sebagai manusia lebih tinggi. Kesepuluh paramartha itu ialah jalan untuk melepaskan diri dari neraka. Karena itulah maka ia harus menjalankan kesepuluh Paramartha ini yaitu: Tapa, Brata, Samadhi, Santa, Sanmanta, Karuna, Karuni, Upeksa, Mudita, dan Maitri.

Tapa artinya meninggalkan keduniawian. Brata yaitu memperkurang kepentingan hidup di dunia ini. Samadhi ialah membiasakan diri memusatkan pikiran di waktu sunyi malam sepi, merenungkan tentang dharma. Santa artinya tidak pernah berbohong. Sanmanta, yaitu satu-satunya keinginan ialah berbuat kebajikan. Karuna ialah cinta dan sayang pada sesama manusia. Karuni ialah cinta kepada segala makhluk hidup termasuk juga binatang. Upeksa artinya mengetahui mana yang baik atau mana yang buruk. Di dalamnya juga termasuk pengetahuan bagaimana cara mengajar manusia lainnya yang bodoh, walaupun mereka nampaknya berbahagia, sehat dan berwajah tampan. Mudita ialah selalu berbahagia, gembira dalam hati, puas pikiran, dan selalu menuruti petunjuk melakukan kewajiban. Maitri artinya selalu berkata sopan dan tidak menyakiti hati orang lain. Sekarang lihatlah daftar-daftar yang tidak suci yang tidak pantas dituruti. Semuanya ada sepuluh, yaitu: Tandri, Kleda, Leja, Kuhaka, Metraya, Megata, $\mathrm{R}$ a g a - s t ri, K u t i l a, Bhaksabhuwana, dan Kimburu.

Tandri yaitu orang yang malas, lemah, suka makan dan tidur saja, enggan bekerja, tidak tulus, dan hanya ingin melakukan kejahatan. Kleda artinya suka menundanunda, pikiran buntu, dan tidak mengerti apa sebenarnya maksudmaksud orang lain. Leja artinya pikiran selalu diliputi kegelapan (tamasika) bernafsu besar. Ingin segala dan gembira jika melakukan kejahatan. Kutila artinya menyakiti orang lain, menyiksa, menyakiti orang miskin dan malang, pemabuk, dan penipu. Tidak seorang pun berkawan baik terhadapnya. Kuhaka artinya orang pemarah selalu mencari-cari kesalahan orang lain, berkata, asal berkata dan sangat keras kepala. Metraya, yaitu orang yang hanya dapat berkata kasar, suka menyakiti dan menyiksa orang lain, sombong pada diri sendiri. "siapa dapat menyamai aku?" pikirnya. Ia suka mengganggu dan melarikan istri orang lain. Megata ialah tidak ada tingkahnya yang dapat dipuji. Meskipun ia berkata atau katakatanya manis dan merendah 
tetapi dibalik lidahnya ada maksud jahat. Ia tidak merasakan kejelekannya, berbuat jahat, menjauhi susila. Ia kejam! Ragastri artinya suka memperkosa perempuan baik-baik dan memandang mereka dengan mata penuh nafsu. Bhaksabhuwana artinya orang yang suka membuat orang lain melarat. Ia menipu orang jujur. Ia berfoya-foya dan berpesta-pesta melewati batas. Ia sombong. Kata-katanya selalu menyakiti telinga. Kimburu yaitu orang yang menipu kepunyaan orang jujur. Ia tidak perduli apa mangsanya itu keluarga, saudara atau kawan. Ia tidak segan mencoba mencuri milik para pendeta. Inilah tingkah orang melakukan kesepuluh dosa itu. Ini tidak bagus.

Ini lagi perilaku yang dinamai nawasanga yang dapat menyebabkan hidup kita menjadi bahagia yaitu: Andrayuga, Gunabhiksama, Sadhuniraga, $\mathrm{W}$ i d a $\mathrm{g} \mathrm{d}$ h a p r a s a $\mathrm{n} \mathrm{a}$, Wirotasadharana, krtaraja-hita, Tyagaprasanna, Suralaksana, Sura-pratyayana yang berjumlah sembilan itu.

Andrayuga artinya menguasai ajaran-ajaran dharma, segala macam pengetahuan, bijaksana, dan tahu akan apa yang baik dan apa yang buruk.

Gunabhiksama artinya jujur akan harta kepunyaan atasannya, selalu dapat mengatasi segala kesukaran, tidak melibatkan diri pada pertentangan-pertentangan yang timbul, seiring sehaluan dengan kehendak umum dunia berbahagia, jika melakukan kebajikan.

Sadhuniragrha artinya jujur terhadap wanita, dan tidak menyakiti sesama manusia.

Widagdhaprasanna artinya tidak termakan oleh ucapan-ucapan tidak benar yang ditujukan kepadanya, dan tidak merasa marah atau sedih, selalu bahagia dan tenang pikirannya.

Wirotas adharana ialah keberaniannya tidak ada bandingannya, tidak bisa kalah dalam perdebatan dan selalu memegang keadilan hukum.

Krtarajahita artinya tidak segansegan mengalah (kalau merasa salah) dan memahami benar isi kitab hukum Kutaramanawa dan lain-lainnya.

Tyagaprasanna artinya tidak mengenal rasa lelah jika sedang melakukan tugas yang dibebankan oleh atasannya.

Suralaksana artinya tidak mengenal rasa takut, selalu cepat dan tidak lamban dalam bertindak. Surapratyayana artinya hormat dan setia pada atasan, tidak pernah mundur dari medan perang, tidak lari dari kesukaran, tetap waspada dalam menjawab atasan.

Semua ini adalah perbuatan Nawasanga yang harus diusahakan melakukannya satu demi satu sampai seluruhnya terlaksana karena hal itu merupakan sesuatu yang sangat baik adanya jika dapat dilaksanakan.

Akhirnya, semua dapat bercermin diri tentang apa yang telah kita lakukan dalam aktivitas bicara kita selama ini. Sudah baik, santun, menyenangkan atau bahkan sebaliknya? pengakuan yang jujur dan upaya untuk berbenah adalah satu tindakan yang baik 
tentunya. Untuk menjadi bijak dalam berbicara ternyata memerlukan prasyarat yang cukup berat, namun semuanya adalah sebuah keniscayaan bagi siapa saja. Terlebih mewujudkan pribadi yang dewasa memerlukan proses yang lebih panjang lagi dan telah dipastikan bahwa fase bijak dalam berbicara ini telah terlampaui dengan sempurna. Bila yang terjadi sebaliknya, anda hendaknya jangan tergesa-gesa menganggap diri telah dewasa atau merasa dewasa, karena hal itu tampaknya masih terasa sangat jauh. Itulah mengapa dalam penjelasan di awal dikatakan bahwa kedewasaan merupakan akumulasi atas banyak dimensi, yang tentunya tidak didapatkan dengan upaya sederhana dan mudah. Oleh sebab itu pengakuan akan diri yang telah merasa dewasa tanpa diiringi sikap terpuji, matangnya banyak hal, termasuk dalam berbicara akan tampak sangat kekanak-kanakan.

\section{Simpulan}

Dari penjelasan terakhir dapat kiranya dipahami bahwa seorang pribadi yang dewasa (dalam arti yang sesungguhnya) sudah tentu memiliki kualitas yang baik dalam setiap bicaranya. Kiranya tidak ada yang mustahil, bila setiap kita berupaya dengan sungguh-sungguh dalam mewujudkan itu. Setidaknya, setiap upaya untuk berbicara yang baik telah mengisyaratkan bahwa kita memiliki hasrat untuk menjadi bijaksana dalam setiap bicaranya, satu harapan mulia untuk mendedikasikan diri menjadi pribadi yang dewasa dikemudian hari, yang di awali dari satu langkah yang paling sederhana, yaitu berbicara yang baik.

\section{Daftar Pustaka}

Cangara, H. Hafied. 2008. Pengantar Ilmu Komunikasi. Jakarta : Raja Grafindo Persada

Masyuhara, Swasti R. 2009. Etika, Petunjuk Lengkap Tata Cara \& Sopan Santun dalam Berbagai Situasi. Bogor : Rumah Pengetahuan

Kajeng, I Nyoman. 1999 . Sarasamuccaya (dengan Teks Bahasa Sanskerta dan Jawa Kuna). Surabaya: Paramit

Pudja, G. 1999. Bhagawad Gita (Pancama Veda). Surabaya : Paramita

Rakhmat, jalaluddin. 2008. Psikologi

Komunikasi. Bandung : Rosda

Saraswati, Sri Chandrasekharendra. 2009. Peta Jalan Veda. Jakarta : Media Hindu

Singh, Dharam Vir. 2007. Hinduisme Sebuah Pengantar. Surabaya : Paramita

Sudharta, Tjok. 2004. Slokantara, Untaian Ajaran Etika (Teks, Terjemahan dan Ulasan). 
Surabaya : Paramita

Suhardana, K.M. 2006. Pengantar Etika

dan Moralitas Hindu (Bahan

Kajian Untuk Memperbaiki

Tingkah Laku). Surabaya :

paramita

Tim, 2008. Kamus Besar Bahasa

Indonesia. $\quad \mathrm{D}$ e p di k n a s.

Gramedia:Jakarta, hal.383 
Jurnal Penerangan Agama Hindu Vol. 15 No. 2, 2017 